\title{
AVALIAÇÃO MORFOLÓGICA DE ACESSOS DE MANDIOCA DA REGIÃO NORTE DO ESTADO DO ESPÍRITO SANTO
}

\author{
Rafael Costa de Sant'Ana' \\ Stanley Bravo Buffon ${ }^{2}$ \\ Lucas Calazans Santos ${ }^{3}$ \\ Ismail Ramalho Haddade ${ }^{4}$ \\ Dayane Littig Barker ${ }^{5}$ \\ Fernanda Favarato ${ }^{6}$ \\ Jasmini Fonseca da Silva ${ }^{7}$ \\ Marcos Moreira ${ }^{8}$ \\ Marcela Tonini Venturini ${ }^{9}$ \\ Sara Dousseau Arantes ${ }^{10}$
}

Resumo: Com o objetivo de avaliar características morfológicas de acessos de mandioca instalou-se um experimento no município de Sooretama, Estado do Espírito Santo. O experimento foi instalado no mês de Maio de 2016, sendo coletados os dados aos 30, 45 e 60 dias após a brotação (DAB). O delineamento experimental utilizado foi em blocos casualizados (DBC), três repetições, com avaliação de 30 acessos de mandioca. As variáveis avaliadas foram: altura de plantas, diâmetro do caule e número de folhas. Houve interação significativa entre os acessos e o tempo de avaliação. O acesso 48 apresentou os maiores valores aos $60 \mathrm{DAB}$ em todas as variáveis analisadas em relação aos demais acessos, que, em contraste, os acessos 62 e 71 obtiveram os menores valores.

Palavras-chave: Manihot esculenta Crantz, Morfologia, Desenvolvimento.

\footnotetext{
1 Instituto Capixaba de Pesquisa, Assistência Técnica e Extensão Rural - INCAPER, Centro Regional de Desenvolvimento Rural - Centro Norte, Linhares, ES, Brasil. E-mail: santanaagronomia@gmail.com.

2 Instituto Capixaba de Pesquisa, Assistência Técnica e Extensão Rural - INCAPER, Centro Regional de Desenvolvimento Rural - Centro Norte, Linhares, ES, Brasil. E-mail: acordatrevo@hotmail.com.

3 Instituto Capixaba de Pesquisa, Assistência Técnica e Extensão Rural - INCAPER, Centro Regional de Desenvolvimento Rural - Centro Norte, Linhares, ES, Brasil. E-mail: lucas.santos@incaper.es.gov.br.

4 Instituto Federal do Espírito Santo - IFES, Campus Santa Teresa, Santa Teresa, ES, Brasil. E-mail: ihadade@gmail.com.

5 Universidade Federal do Espírito Santo - UFES, Centro Universitário Norte do Espírito Santo - CEUNES, São Mateus, ES, Brasil. E-mail: dayanelittig@hotmail.com.

6 Instituto Capixaba de Pesquisa, Assistência Técnica e Extensão Rural - INCAPER, Centro Regional de Desenvolvimento Rural - Centro Norte, Linhares, ES, Brasil. E-mail: fernandafavarato2@hotmail.com.

7 Instituto Capixaba de Pesquisa, Assistência Técnica e Extensão Rural - INCAPER, Centro Regional de Desenvolvimento Rural - Centro Norte, Linhares, ES, Brasil. E-mail: jsmifonseca@gmail.com.

8 Instituto Capixaba de Pesquisa, Assistência Técnica e Extensão Rural - INCAPER, Centro Regional de Desenvolvimento Rural - Centro Norte, Linhares, ES, Brasil. E-mail: marcosmoreira34@gmail.com.

9 Instituto Capixaba de Pesquisa, Assistência Técnica e Extensão Rural - INCAPER, Centro Regional de Desenvolvimento Rural - Centro Norte, Linhares, ES, Brasil. E-mail: cosalin2@yahoo.com.br.

10 Instituto Capixaba de Pesquisa, Assistência Técnica e Extensão Rural - INCAPER, Centro Regional de Desenvolvimento Rural - Centro Norte, Linhares, ES, Brasil. E-mail: saradousseau@yahoo.com.br.
} 